\title{
Reproductive Isolation, Reproductive Mode, and Sexual Selection: Empirical Tests of the Viviparity- Driven Conflict Hypothesis
}

\author{
Seth W. Coleman, ${ }^{1, *}{ }^{\star}$ April Harlin-Cognato, ${ }^{2, *}$ and Adam G. Jones ${ }^{3}$ \\ 1. Biology Department, Gonzaga University, Spokane, Washington 99208; and Centro de Investigación Científica de las Huastecas \\ “Aguazarca," Calnali, Hidalgo, Mexico; 2. Department of Zoology, Michigan State University, East Lansing, Michigan $48824 ; 3$. \\ Department of Biology, Texas A\&M University, College Station, Texas 77843
}

Submitted May 23, 2008; Accepted September 16, 2008; Electronically published January 27, 2009

Online enhancement: appendix.

\begin{abstract}
Aвstract: A central goal in evolutionary biology is to elucidate general mechanisms and patterns of species divergence. The viviparity-driven conflict (VDC) hypothesis posits that intense motherembryo conflict associated with viviparity drives rapid reproductive isolation among viviparous species, is intensified by multiple paternity, and reduces female reliance on precopulatory cues in mate choice. We tested these predictions using comparisons of oviparous and viviparous fishes. Consistent with the VDC hypothesis, we found that, relative to oviparous species, only closely related viviparous fishes are known to hybridize. Also in support of the VDC hypothesis, we found that (1) elaborate male sexual ornamentation may be more common in viviparous species with relatively low levels of maternal provisioning of embryos compared with those with high levels of provisioning and (2) the degree of multiple paternity is higher in viviparous species than in oviparous species. In contrast to a prediction of the VDC hypothesis, we found no relationship between the degree of multiple paternity and elaborate male sexual ornamentation, although statistical power was quite low for this test. Whereas overall our results strongly support the central tenet of the VDC hypothesis - that reproductive mode affects rates of evolution of reproductive isolation and the strength of sexual selection-they cannot rule out two alternative models we propose that may also explain the observed patterns.
\end{abstract}

Keywords: speciation, reproductive isolation, antagonistic coevolution, viviparity, sexual selection, matrotrophy.

\section{Introduction}

Long after Darwin (1871) marveled at "endless forms most beautiful," species divergence and the evolution of reproductive isolation among populations remain central issues in evolutionary biology (Coyne and Orr 2004). Repro-

* These authors contributed equally to this study.

† Corresponding author; e-mail: scoleman@bio.tamu.edu.

Am. Nat. 2009. Vol. 173, pp. 291-303. (C) 2009 by The University of Chicago. 0003-0147/2009/17303-50490\$15.00. All rights reserved.

DOI: $10.1086 / 596542$ ductive isolation may be pre- or postcopulatory (Dobzhansky 1937; Mayr 1963; Birkhead and Møller 1998), and the stage at which reproductive isolation occurs can have important consequences for species divergence (Coyne and Orr 1989, 1997; Gleason and Ritchie 1998; Bordenstein et al. 2001; Mendelson 2003). Recently, it has been suggested that genetic conflict between mothers and embryos plays an important role in the evolution of postzygotic reproductive isolation (Zeh and Zeh 2000, 2008). Haig (1993, 1996a, 1996b, 2004, 2006) has investigated this conflict extensively in humans (although not in the context of speciation), arguing that the conflict reflects selfish interactions between three genetic "factions" during pregnancy: maternal genes shared by the mother and fetus (inherited maternal haplotypes), genes present in the mother but not in the fetus (noninherited maternal haplotypes), and genes present in the fetus but not in the mother (paternally derived fetal haplotypes; reviewed in Haig 2006). Each of these factions acts selfishly with respect to the distribution of maternal resources. Paternally inherited haplotypes are predicted to drive individual embryos to garner maximum resources, even at the expense of the mother and siblings, whereas maternal haplotypesespecially those present only in the mother-are predicted to control the distribution of maternal resources to maximize reproductive output of multiple offspring with haplotypes that are most favorable for the mother's haplotype (reviewed in Haig 2006). With this model in mind, Zeh and Zeh (2000) proposed the viviparity-driven conflict (VDC) hypothesis to help explain broad patterns of reproductive isolation among species.

The VDC hypothesis posits that reproductive mode influences the rate at which postzygotic reproductive isolation evolves (Zeh and Zeh 2000, 2008). The central tenet of this hypothesis is that internal gestation in viviparous species creates the potential for antagonistic coevolution 
(e.g., Holland and Rice 1998) between maternal and paternal genes expressed by developing embryos (i.e., Haig 2006). Zeh and Zeh $(2000,2008)$ propose that viviparity, characterized by extensive fetomaternal interaction (reviewed in Haig 2006), favors the evolution of aggressive paternal genomes that are expressed in embryos and that bias the acquisition of maternal resources to embryos; in response, females are predicted to express genes during pregnancy that suppress embryonic manipulation of maternal resources. For example, the conflicting effects of the paternally expressed insulin-like growth factor II (Igf2), the product of which functions primarily in promoting the transfer of resources from the mother to the embryo, and the maternal insulin-like growth factor type II receptor (Igf2r), whose product degrades the product of Igf2, may reflect antagonistic coevolution driven by mother-embryo conflict (Zeh and Zeh 2000; Chao and D'Amore 2008). Zeh and Zeh (2000, p. 940) argue that such "viviparitydriven conflict should generate perpetual antagonistic coevolution ... between genes expressed in embryonic development and genes involved in maternal reproductive physiology, thereby greatly accelerating the rate at which postzygotic isolation evolves between [viviparous] populations." Thus, reproductive isolation should arise more rapidly among viviparous species than among oviparous species.

According to the VDC hypothesis, the intensity of fetomaternal interaction determines the rate at which this coevolutionary arms race proceeds, with more rapid coevolution expected in species that display extensive interaction between mother and fetus. Thus, viviparous species with complex organs for fetomaternal exchange (such as the placenta of mammals) are predicted to evolve postzygotic reproductive incompatibility more rapidly than oviparous species. Consistent with this prediction, Zeh and Zeh (2000) report that, within oviparous taxa (birds and frogs), distantly related species are able to hybridize, whereas only relatively closely related placental mammals are able to produce viable hybrids. In addition, because extensive mother-embryo conflict may favor the evolution of an aggressive paternal genome, Zeh and Zeh (2000, 2008) predict (1) a positive association between the degree of fetomaternal interaction and multiple paternity, where embryos of different males compete within the womb for access to maternal resources, and (2) that multiple paternity thus reduces female reliance on precopulatory cues in mate choice; in other words, the "arena" for sexual selection has moved from precopulatory to postcopulatory.

Here we test several predictions of the VDC hypothesis using comparisons among viviparous and oviparous fishes. First, if fetomaternal conflict drives the rate of evolution of reproductive isolation, we predict that, relative to oviparous fishes, only closely related viviparous fishes should be able to produce viable hybrids. Second, if VDC generates genetic incompatibility within populations, then viviparous species should have higher rates of multiple paternity (as a means of avoiding fertilizations from genetically incompatible mates) than oviparous species. Third, if substantial maternal provisioning intensifies mother-embryo conflict, and if this intensification reduces female reliance on precopulatory cues in mate choice (Zeh and Zeh 2000), then males of species with relatively high levels of maternal provisioning should be less elaborately ornamented than males of species with relatively low levels of maternal provisioning. Fourth, if multiple paternity intensifies embryonic competition for maternal resources, which in turn selects for increased expression of maternal genes that suppress embryonic sequestration of resources, then this increase in female control of embryos should result in a reduction in female reliance on precopulatory male cues in mate choice.

\section{Material and Methods}

\section{Divergence Times and Hybridization in Fishes}

The literature on hybridizability in fishes is extensive, combining information from aquarists, aquaculturalists, and research scientists. The literature on divergence times in fishes is less well developed. We found 89 interspecific crosses for fishes in which we were also able to find approximate divergence times between the species crossed (table A1 in the online edition of the American Naturalist). We grouped crosses on the basis of divergence times and compared the relationship between hybridizability and divergence times among fishes with those relationships in mammals, birds, and frogs as reported by Zeh and Zeh (2000).

\section{Degree of Multiple Paternity and Reproductive Mode}

To test the prediction that VDC favors the evolution of multiple paternity (e.g., Zeh and Zeh 2000, p. 940), we compared the percentage of broods with multiple paternity between oviparous and viviparous fishes. To make this comparison, we searched the literature and summarized studies that reported results on genetic patterns of paternity in fishes (table A2).

\section{Maternal Provisioning of Embryos and Male Sexual Ornamentation}

To test the VDC hypothesis prediction that, with increasing maternal provisioning of embryos, there should be a corresponding decrease in female reliance on precopulatory cues in mate choice (e.g., Zeh and Zeh 2000), we inves- 
tigated the relationship between the degree of maternal provisioning and sexual dimorphism in the live-bearing fish genus Poeciliopsis and in the halfbeaks (family Zenarchopteridae). For both groups, we used the amount of nutrition provided by the mother to an embryo during gestation as an indirect measure of the intensity of motherembryo interaction, under the assumption that, as maternal provisioning of embryos increases, so too does the propensity for fetomaternal conflict (Zeh and Zeh 2000, 2008). In analyses involving Poeciliopsis species, we used the matrotrophy index, which is defined as the ratio of the mass of newly hatched fry to the mass of egg (sensu Reznick et al. 2002). In Poeciliopsis species without maternal provisioning, the matrotrophy index is expected to be close to 1.0, indicating nutritional supplementation only from the yolk of the embryo. A matrotrophy index much larger than 1.0 suggests that the embryo receives extensive nutritional supplementation from the mother during development (e.g., Reznick et al. 2002). To measure maternal provisioning of embryos in Hemiramphidae, we used data from Meisner and Burns (1997) showing the percent weight gained or lost by embryos between critical stages of development. A large increase in weight gain implies a high degree of maternal provisioning.

We used sexual dimorphism as a proxy for female use of precopulatory cues in mate choice. We considered a species to be sexually dimorphic only if males had elaborate secondary sexual ornaments such as bright breeding coloration and/or ornate morphology (elongate fins, cephalic humps, etc.). For our analyses, we did not classify species as sexually dimorphic if the sexes differed solely in body size. Accurate descriptions of male ornamentation in Poeciliopsis species and the halfbeaks were provided by D. N. Reznick and B. B. Collette, respectively, and were confirmed in the literature wherever possible.

\section{Statistical and Comparative Analyses}

The close evolutionary relationships among species within Poeciliopsis and among the halfbeaks required that we control for potentially confounding effects because of a lack of evolutionary independence among species (Felsenstein 1985). Thus, we grouped species by genus for all analyses involving multiple genera and calculated the mean variable of interest for each genus such that each genus represented only a single data point in our data set. We also used the Poeciliopsis molecular phylogeny (Mateos et al. 2002) to test for correlations between male ornamentation and maternal provisioning of embryos while controlling for phylogenetic history. We used Mesquite, version 1.12 (Maddison and Maddison 2006), to reconstruct the character states of interest, that is, male ornamentation and matrotrophy index. The "mirror tree" function in Mesquite al- lowed us to conduct "heuristic visualizations" (Maddison and Maddison 2006) before proceeding with more quantitative tests. Because we scored male ornamentation as a discrete binary character (present or absent), independent contrasts were invalid, and thus we used pairwise comparisons to test for character correlations as described by Read and Nee (1995) and Maddison (2000). Because of the high frequency of polytomies in the halfbeak phylogeny (Meisner 2001; Reznick et al. 2007), we were unable to conduct meaningful statistical tests for phylogenetic independence. Heuristic visualization of the mirrored cladogram, however, did not reveal any clear association between male ornamentation and matrotrophic index in this group (see "Results").

One-tailed Student's $t$-tests were used to compare mean levels of multiple paternity between oviparous and viviparous fishes and between species with and without sexually ornamented males. Because of violations of assumptions of parametric tests (Sokal and Rohlf 1995), we used MannWhitney $U$-tests to compare the mean levels of maternal provisioning between species with and without elaborately ornamented males within Poeciliopsis and Hemiramphidae. Power analyses were performed using Statistica, version 6.0 (StatSoft); statistical power is reported for tests showing nonsignificant differences.

\section{Results \\ Divergence Times and Hybridizability}

Our analysis of the relationship between divergence times and hybridizability shows that fishes appear to be intermediately hybridizable relative to mammals, birds, and frogs (fig. 1). The VDC hypothesis argues that, because of mother-embryo conflict, reproductive isolation arises more rapidly among viviparous species than among oviparous species (Zeh and Zeh 2000, 2008). We tested this prediction by comparing hybridizability and divergence times between viviparous and oviparous fishes, and we found that the time since common ancestry was significantly longer for hybridizing pairs of oviparous species ( $n=72$ ) than for hybridizing pairs of viviparous species ( $n=12$; oviparous species, $14.76 \pm 1.40$ million years; viviparous species, $7.42 \pm 0.97$ million years; $t=-2.60$, $\mathrm{df}=82, P=.01$; table A1). Our results support this prediction of the VDC hypothesis, that is, that viviparous species hybridize only with close relatives, compared with oviparous species (fig. 2; table A1).

\section{Degree of Multiple Paternity and Reproductive Mode}

A secondary prediction of the VDC hypothesis is that the high potential for genetic incompatibility among mates 

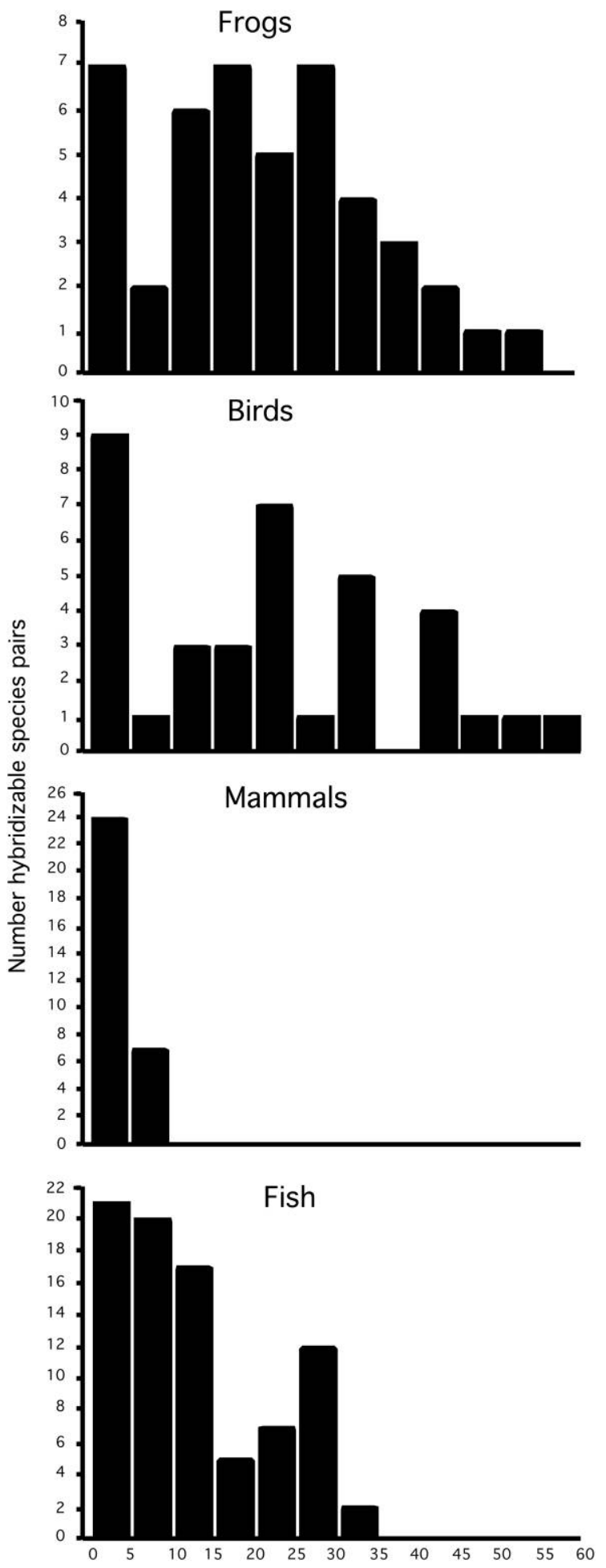

Estimated time since common ancestor (mya)

Figure 1: Relationship between number of hybridizable species and estimated time since common ancestor for mammals, birds, and frogs (data adapted from Zeh and Zeh 2000) and fishes. mya = millions of years. should favor the evolution of multiple paternity in viviparous taxa (Zeh and Zeh 2000, p. 940). To test this prediction, we searched the literature for studies of fishes that report the frequency of genetic multiple paternity, and we compared these reported levels among oviparous and viviparous fishes (table A2). In support of the prediction of the VDC hypothesis, the degree of genetically confirmed multiple paternity was higher in viviparous species $(\bar{x}=$ $62.9 \pm 8.66)$ than in oviparous species $(\bar{x}=40.44 \pm 6.8$; $t=-1.89$, $\mathrm{df}=27, P=.035)$. However, this result may stem in part from the greater ease with which multiple paternity can be detected in viviparous species compared with oviparous species.

\section{Degree of Multiple Paternity and Male Sexual Ornamentation}

Zeh and Zeh $(2000,2008)$ argue that viviparity favors the evolution of multiple paternity, which increases female utilization of postcopulatory mate choice mechanisms, thereby reducing female reliance on precopulatory male signals in mate choice. In contrast to this prediction of the VDC hypothesis, we found no relationship between the degree of multiple paternity in species with $(\bar{x}=$ $52.17 \pm 8.81)$ and without $(\bar{x}=44.03 \pm 9.16)$ male ornamentation $(t=-0.62$, df $=28, P=.22$; power $=$ 0.86; table A2).

\section{Maternal Provisioning and Male Sexual Ornamentation}

A corollary prediction of the VDC hypothesis is that, in species with high maternal investment in embryos, there should be reduced reliance by females on precopulatory sexual signals in mate choice where fetomaternal conflict is most extreme (Zeh and Zeh 2000). Thus, we predicted that species with elaborate male sexual ornamentation would have lower maternal investment in embryos compared with sexually monomorphic species. We did not find support for this prediction either in Poeciliopsis species $(Z=-1.19, P=.24$, power $=0.24$; tables $1, \mathrm{~A} 3)$ or in two assays of maternal provisioning in the halfbeaks (matrotrophic index: $Z=-0.89, P=.37$, power $=0.20$; tables 1, A4; percent dry weight gained/lost by embryos: $Z=-1.24, P=.21$, power $=0.18$; tables 1 , A5). It should be noted, however, that small sample sizes combined with large variances may contribute to this lack of statistically significant support for the VDC hypothesis. However, there are large nonsignificant differences between sexually dimorphic and monomorphic species in mean levels of matrotrophy (table 1), and this trend is in the direction that is consistent with the predictions of the VDC hypothesis.

Pairwise phylogenetic comparisons (Read and Nee 1995; 


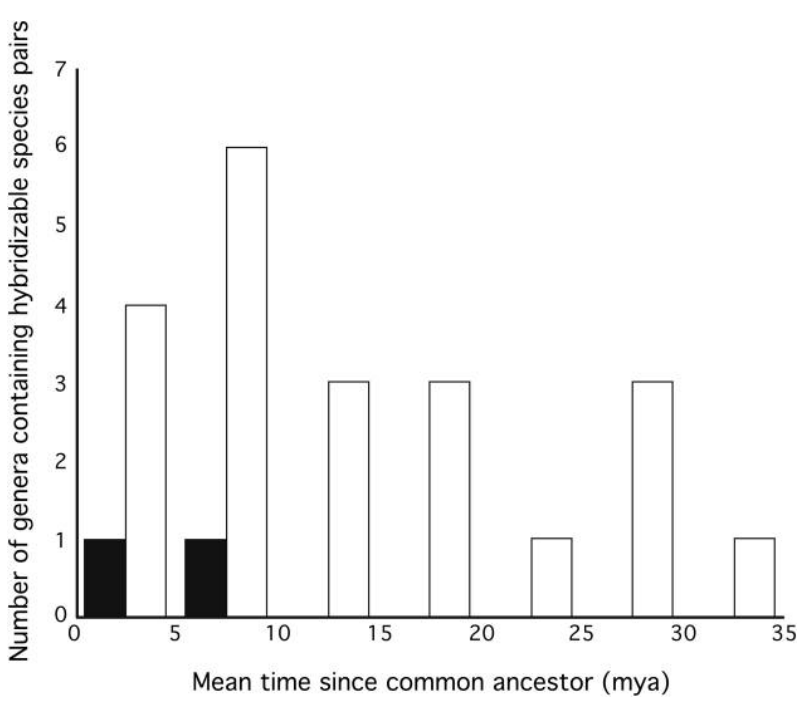

Figure 2: Relationship between reproductive mode and the mean time since common ancestor (data are from table A1 in the online edition of the American Naturalist). Supporting the predictions of the viviparitydriven conflict hypothesis, this figure suggests that, within genera and relative to oviparous species (open bars), only closely related viviparous species (solid bars) are able to hybridize. mya $=$ millions of years.

Maddison 2000) within the Poeciliopsis phylogeny (Mateos et al. 2002; fig. 3) revealed no significant phylogenetic correlation $(P=.25)$ between levels of maternal provisioning and male ornamentation. Unfortunately, due to the lack of available information on male ornamentation and maternal provisioning, phylogenetic tests were invalid in the halfbeaks (fig. 4).

\section{Discussion}

The VDC hypothesis posits that reproductive mode has important effects on rates of evolution of postzygotic reproductive isolation among populations, and it has been proposed as a novel hypothesis to explain general patterns of species divergence (Zeh and Zeh 2000, 2008). Overall, we found strong support for the central predictions of the VDC hypothesis. In particular, our results show that (1) compared with oviparous fishes, only relatively closely related viviparous fishes are known to hybridize (fig. 2); (2) the degree of multiple paternity tends to be higher in viviparous species than in oviparous species; and (3) elaborate male ornamentation may be more common in viviparous fishes with low levels of matrotrophy compared with viviparous species with a high degree of maternal provisioning (table 1).

In contrast to predictions of the VDC hypothesis, we did not find evidence for a negative correlation between male ornamentation and maternal provisioning within
Poeciliopsis (fig. 3), nor did we find a relationship between the degree of multiple mating and elaborate male ornamentation. One explanation for these results is that our measure of male ornamentation is oversimplified: not only is there a high degree of variation in sexual cues among and within species, but also our measure did not include less obvious traits, such as ultraviolet coloration, that are known to be important in mate choice in fishes (Smith et al. 2002; Boulcott et al. 2005; Rick et al. 2006; Rick and Bakker 2008). Furthermore, we used the number of broods (\% broods; table A2) exhibiting multiple paternity as a proxy for polyandry, but multiple mating by a female and multiple paternity within a brood are not equivalent in viviparous fishes. For example, there is greater potential for females in viviparous species to bias paternity after copulation than for females in oviparous species. Thus, rates of multiple mating by females in viviparous species may be underestimated, especially when these measures are made on the basis of the genotypes of late-stage fetuses or postnatal individuals. On the other hand, viviparity allows for maternity to be reliably determined (viviparous females are collected with their full complement of offspring), which may result in a bias in favor of detecting multiple paternity in viviparous relative to oviparous taxa. In addition to these potential biases, the degree of multiple mating is likely to be influenced by a wide range of factors (e.g., population density, alternative mating tactics, habitat stability). There is some evidence that these factors affect the rate of polyandry (and multiple paternity) in different populations of the same species of viviparous fishes (e.g., Soucy and Travis 2003), making comparisons of average paternity within, as well as between, species potentially problematic. Therefore, although our results support the primary predictions of the VDC hypothesis overall, we suggest that further comparative empirical tests, studies of reproductive physiology and the genetic mechanisms underlying fetomaternal interactions, as well as rigorous theoretical modeling are needed to assess the generality of the VDC hypothesis in explaining broadscale patterns of spe-

Table 1: Relationship between degree of maternal provisioning of embryos and male ornamentation

\begin{tabular}{|c|c|c|}
\hline $\begin{array}{l}\text { Measure of maternal } \\
\text { provisioning, species }\end{array}$ & $\begin{array}{l}\text { Ornamented } \\
\text { males }( \pm S E)\end{array}$ & $\begin{array}{l}\text { Nonornamented } \\
\text { males }( \pm \text { SE })\end{array}$ \\
\hline \multicolumn{3}{|l|}{ Matrotrophic index: } \\
\hline Poeciliopsis $^{\mathrm{a}}$ & $8.48 \pm 7.55$ & $19.75 \pm 11.57$ \\
\hline Halfbeaks ${ }^{\mathrm{b}}$ & $.92 \pm .57$ & $55.9 \pm 47.66$ \\
\hline \multicolumn{3}{|l|}{ \% Dry weight: } \\
\hline Halfbeaks ${ }^{c}$ & $24.21 \pm 11.85$ & $222.76 \pm 86.19$ \\
\hline
\end{tabular}




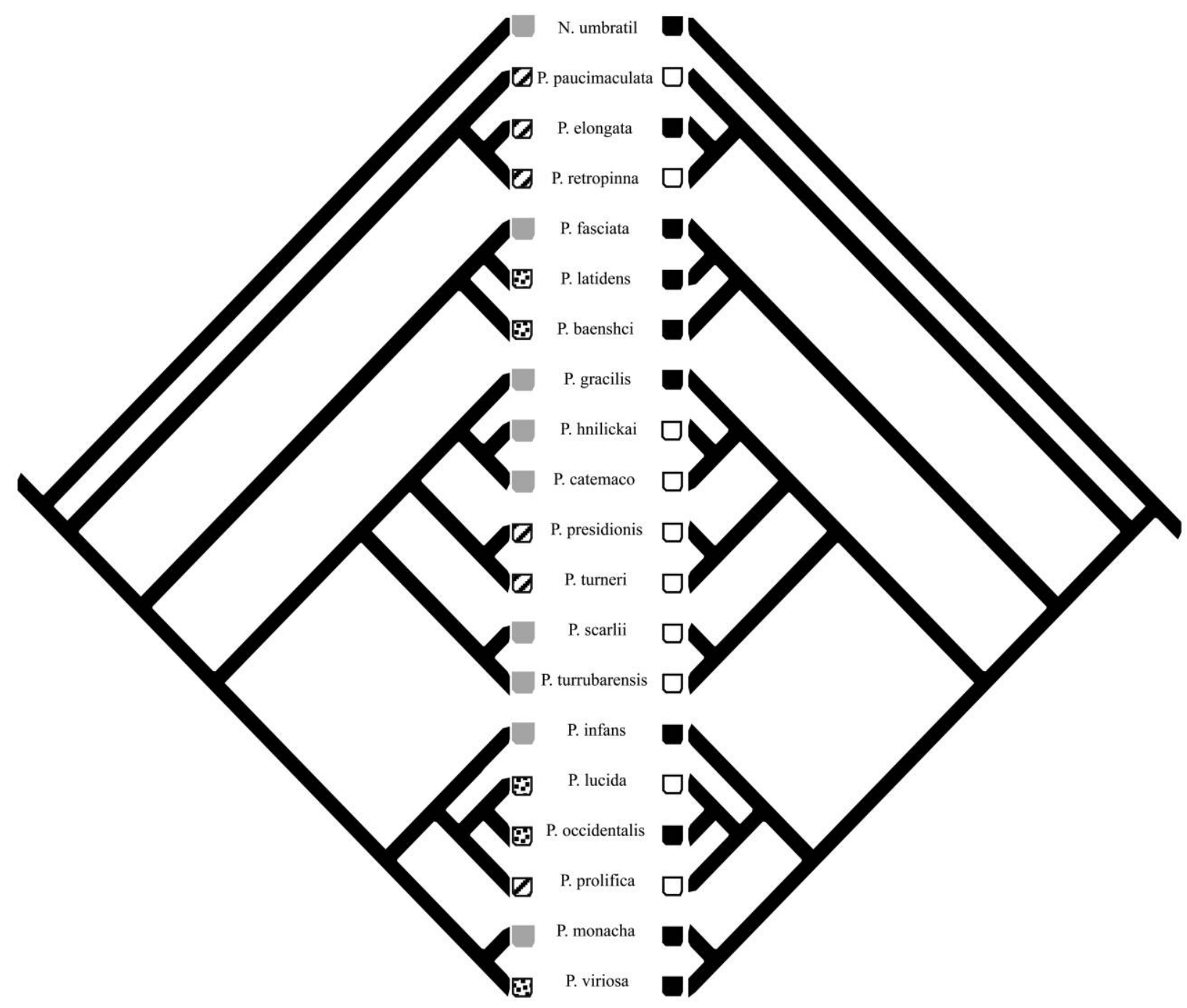

Figure 3: Mirror images of the Poeciliopsis phylogeny (Mateos et al. 2002) showing the distribution of maternal provisioning levels (Reznick et al. 2002) — none (gray squares), moderate (stippled squares), extensive (striped squares) - in the left tree and the distribution of male ornamentationornamented males (black squares), unornamented males (white squares) - in the right tree. Pairwise comparisons to test for character correlations (Read and Nee 1995; Maddison 2000) were nonsignificant $(P=.25)$, suggesting that there is no phylogenetic explanation for the relationship we found between male ornamentation and maternal provisioning. The outgroup is Neoheterandria umbratil (Mateos et al. 2002).

cies divergence and reproductive isolation. No doubt, the body of sexual conflict theory (reviewed in Parker 2006), which may be highly relevant to tests of the VDC hypothesis, will be useful for this investigation. Hayashi et al. (2007, p. 526), for instance, conclude that the "evolutionary dynamics of sexual conflict strongly depend on the genetic details." If this statement is true for sexual conflict, then it follows that it may be true for fetomaternal conflict as well.

As evidence in support of the VDC hypothesis, Zeh and Zeh (2000) showed that, relative to oviparous taxa (i.e., frogs and birds), only relatively closely related placental mammals have been known to hybridize. They argue that this difference arises from the mother-embryo conflict inherent in viviparous species, in which the fetomaternal interface (via the placenta) is particularly well developed compared with oviparous and other viviparous vertebrates. Our analysis of hybridizability, divergence times, and reproductive mode in fishes supports this central tenet of Zeh and Zeh's (2000) model: relative to oviparous species, only closely related viviparous fishes are known to hybridize (fig. 2). In viviparous fishes, the rate of decline in hybrid embryo viability is markedly more rapid than it is in oviparous fishes, with complete loss of viability within 

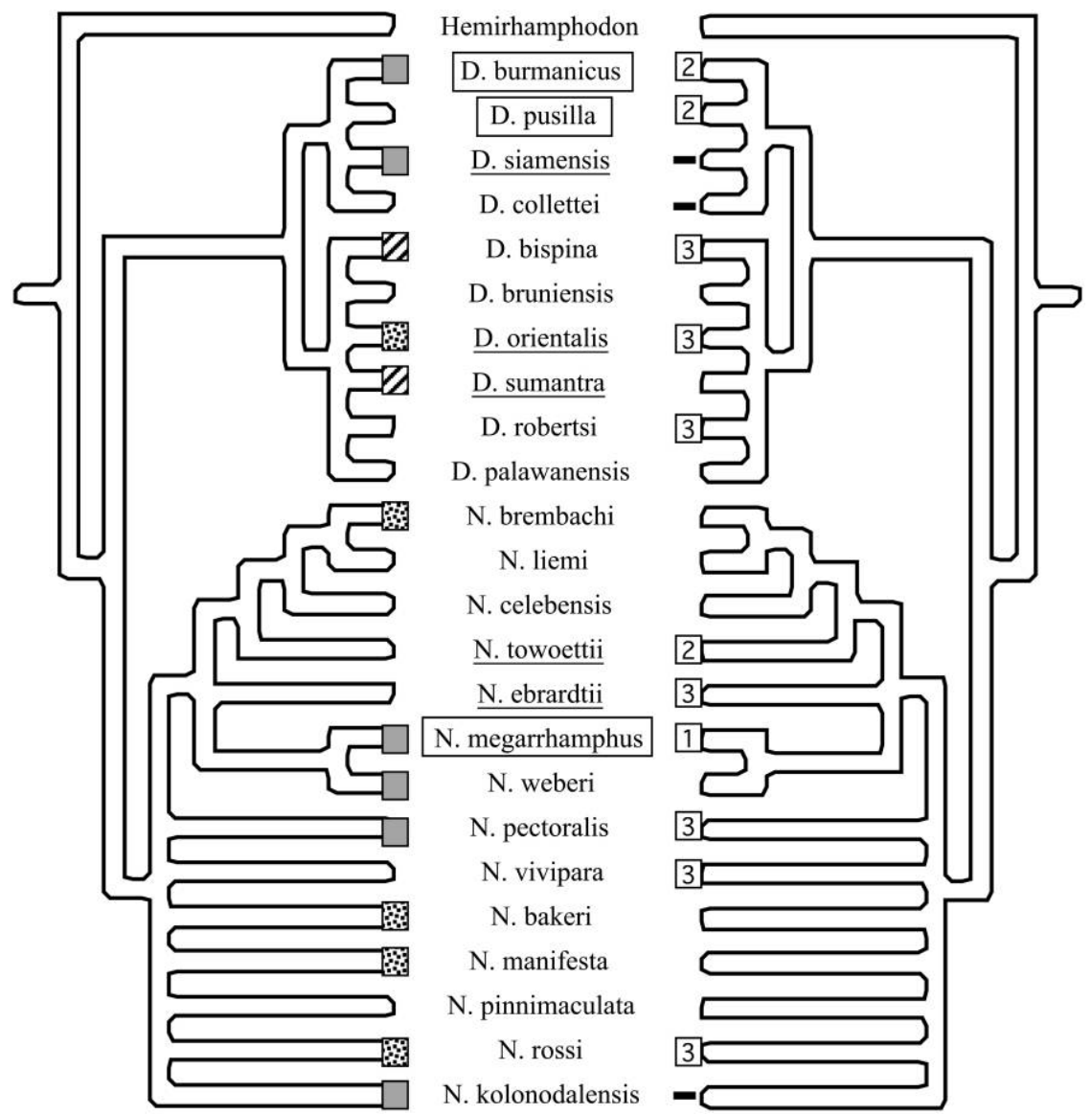

Figure 4: Mirror images of the halfbeak phylogeny (Reznick et al. 2007) showing the distribution of male ornamentation—ornamented males (species boxed), unornamented males (species underlined), unknown (species not marked)—and maternal provisioning levels, measured two ways: (1) in the left tree, matrotrophic index (Reznick et al. 2007): none (gray squares), moderate (stippled squares), extensive (striped squares); and (2) in the right tree, percent embryonic weight lost or gained (Meisner and Burns 1997): lost (minus sign), small gain (boxed 1), moderate gain (boxed 2), substantial gain (boxed 3). Because of the lack of available information on male ornamentation and maternal provisioning, phylogenetic tests were not possible.

10 million years after divergence (fig. 2; table A1). Recent data from hybrid crosses between two populations of the least killifish (Heterandria formosa) demonstrate how intraspecific hybrid embryo inviability can evolve in as few as 100,000 years in viviparous fishes (Schrader and Travis 2008). In contrast, oviparous fishes lose their ability to hybridize much more slowly, with some hybrid embryo viability observed in taxa that diverged as long as 35 million years ago. In a recent study, Bolnick and Near (2005) provided strong evidence to support the reduced tempo of hybrid inviability in oviparous fishes. Using a phylogeny of centrarchid fishes with well-corroborated dates of divergence (e.g., Near et al. 2005) and a series of hybrid crosses, they found that the average hybrid embryo viability of centrarchids declines at a rate of only $3.13 \%$ per 1 million years, with a minimum divergence time of 25 million years for complete embryonic inviability. Remarkably, in these fishes, there is a period of 6 million years in which there is little or no loss in viability. In fact, several recently diverged species pairs exhibit heterosis. Although our data on divergence times of viviparous fishes were necessarily limited to a single family (Poeciliidae), the findings of Bolnick and Near (2005), together with the data on hybridizability in other oviparous taxa (table A1), indicate that VDC may be at least partially responsible for the marked difference between oviparous and viviparous fishes in the rate at which hybrid viability declines with increasing divergence time.

Zeh and Zeh $(2000,2008)$ suggest that the rapid loss of hybrid viability between oviparous species can be explained, in part, by close fetomaternal interactions in viviparous species that favor the evolution of aggressive pa- 
ternal genomes. Thus, the VDC hypothesis predicts that the rate of postzygotic isolation will be more rapid among populations with high between-population variation in the number of males with which females mate. This prediction has been supported by a recent study of the viviparous, matrotrophic least killifish ( $H$. formosa), where increased hybrid inviability has been observed between two populations with large differences in rate of polyandry (Schrader and Travis 2008). However, in relation to the VDC hypothesis, we suggest that not only the rate but also the type of polyandry may be an important determinant of the rate of postzygotic divergence. For example, neither the study of the killifish nor our study distinguishes between single-brood polyandry, in which a single brood has multiple fathers, and superfetation, a type of polyandry potentially widespread in viviparous fishes (Thibault and Schultz 1978; Reznick and Miles 1989) in which multiple broods, usually with different fathers, are present at different developmental stages in a single female at the same time (Turner 1937, 1940; Scrimshaw 1944). The difference between single-brood and superfetation polyandry is that, in the former, sperm from different males fertilize all embryos in a single brood at approximately the same time, whereas in the latter, the female carries embryos from fertilization events that occurred at different times. The VDC hypothesis suggests that the evolution of an aggressive paternal genome favors the evolution of polyandry, and superfetation may add an additional layer of intensity to the antagonistic interaction between paternal genomes because broods differ in the quantity and type of resources required at different stages of development. Thus, one might expect greater conflict and a concomitant acceleration in divergence between populations of species in which superfetation is possible, such as the least killifish (Soucy and Travis 2003), compared with species in which single-brood polyandry is the norm.

In addition, despite general support for the predictions of the VDC hypothesis in our data, one of the main mechanisms that might facilitate VDC, namely, genomic imprinting, may not be as important in fishes as it is in mammals. The placental structure in viviparous fishes is functionally similar in many ways to the mammalian placenta, but it is developmentally derived from different tissue. In mammals, there are specific parent-of-origin genes with tissue-specific imprinting, both of which are required for normal embryonic development (McGrath and Soulter 1984; Surani et al. 1984; Hore et al. 2007). Parent-of-origin (e.g., "imprinted") gene expression is determined during gametogenesis, where modifications to certain genes determine whether they are expressed by either the maternal or the paternal genomes in the developing embryo (Tilghman 1999; Reik and Walter 2001; Morison et al. 2005; Vrana 2007). In fishes, there is no known parent-of-origin effect during development. For example, Igf2, which is paternally expressed in mammals (reviewed in Vrana 2007), is biallelically expressed in fish species for which this topic has been investigated (Lawton et al. 2005). Taken at face value, this suggests that parent-of-origin gene expression may not be important in the evolution of hybrid inviability in fishes. However, a recent study suggests that, despite bialleleic expression of $I g f 2$ in viviparous fishes, this gene is expressed in the pericardial sac of developing least killifish embryos, a structure that facilitates the provisioning of nutrients from mother to offspring (O'Neill et al. 2007). Furthermore, examination of the molecular evolution of $I g f 2$ across poeciliids suggests that positive Darwinian selection has been shaping this locus, which is potentially related to a function involved in nutritional provisioning (O’Neill et al. 2007). The VDC hypothesis is not critically dependent on genomic imprinting, because maternal-offspring conflict is certainly possible in the absence of epigenetic effects. However, these results suggest that, despite the lack of tissue-specific imprinting of this locus, its link to matrotrophy makes it a likely contender in the antagonistic conflict that leads to rapid hybrid embryo inviability, especially in matrotrophic viviparous fishes.

We propose two alternative models to explain the relatively low rates of hybridization among viviparous fish taxa compared with oviparous taxa. The first model, which we call the "Rube Goldberg model," is based on the notion that a complex machine that performs a simple function is easier to break than a simple machine that performs the same function. A similar idea applies to the divergence of fertilization modes. The central goal of mating is simply to fertilize eggs with sperm. In most oviparous fish species, this process consists of courtship and the coordinated release of gametes into the water column. In these species, precopulatory divergence can be achieved only by divergence in species recognition or courtship cues or by eggsperm incompatibility. However, viviparous species face the much more difficult challenge of transferring gametes directly into the body of another individual. Thus, in addition to species recognition, courtship, and gamete compatibility, viviparous species have several additional targets for reproductive divergence. These additional targets include the morphological apparatus for gamete transfer and the ability of the male gametes to survive in and navigate the female reproductive tract. We hypothesize that neutral divergence among lineages in reproductive behavior and structures alone could account for the lower propensity of viviparous (as opposed to oviparous) species to form hybrids, because such divergence will have a more important impact on reproduction in viviparous species.

A second model that can help explain our results involves the differences in the costs of mating to females of 
viviparous and oviparous species. These differential costs favor the evolution of female preferences for male sexual signals used to discriminate among potential mates before copulation in viviparous species. This model appears to work only if viviparous females can more easily reduce the costs of mating by choosing to mate with preferred males than females in oviparous species can. In other words, we predict a stronger negative relationship between perceived male quality and the costs of mating in viviparous species than in oviparous species. There may be reason to expect such a pattern, however. Fertilization is internal in all mammals and viviparous fishes. Thus, successful fertilization requires the male genitalia to penetrate, or attach to, the female genitalia. In many viviparous fishes, males have evolved highly specialized genitalia that manipulate female reproductive physiology and can cause significant injury to females during copulation (Rosen and Bailey 1963). In the viviparous poeciliid fishes, for instance, males impregnate females with a gonopodium, a bony intromittent organ armed with hooks, spines, and claws (Rosen and Bailey 1963). During copulation, the gonopodium attaches to the female's genitalia and is freed only after vigorous shaking, which frequently causes female bleeding (Constantz 1989). This direct, prolonged, and potentially injurious contact between male and female genitalia increases the likelihood of transferring sexually transmitted diseases or parasites during mating in viviparous species relative to oviparous species (in which females release eggs before they are fertilized). Hence, costs associated with viviparity should favor the evolution of female preferences that allow for discrimination among males before copulation if the female can avoid these costs of mating by choosing better mates. Indeed, many viviparous fishes have become models for the study of sexual selection primarily because of active female assessment of precopulatory cues during mate choice (Houde 1997; Ryan and Rosenthal 2001). Furthermore, although direct tests of female mammals' preferences for male display traits are rare, the use of precopulatory male signals in mate choice by female mammals is likely widespread (Huck and Banks 1982; Lennington and Egid 1985; Reece-Engel 1988; Clutton-Brock et al. 1989; McComb 1991; Cooper and Hosey 2003; Fisher et al. 2003a, 2003b; Hohoff et al. 2003; Waitt et al. 2003; Craul et al. 2004). In addition, comparative phylogenetic data show that viviparous fish species tend to be more sexually dichromatic than oviparous species (Mank and Avise 2006), a pattern that we would predict under this second model but not under the VDC model.

In summary, our comparative analysis of patterns of reproduction and hybridization in fishes strongly supports the central predictions of the VDC hypothesis. In particular, our data support that (1) viviparous species lose the ability to produce viable hybrids more rapidly than ovip- arous species; (2) viviparous, highly matrotrophic species are less reliant on precopulatory cues than are viviparous species with low levels of matrotrophy, a result that supports the idea that postcopulatory sexual selection is important in some viviparous taxa; and (3) on average, viviparous species are more polyandrous than oviparous species. However, in contrast to the predictions of the VDC hypothesis, our data do not support a negative relationship between multiple paternity and sexual dimorphism. Our analysis consequently provides no evidence for a causal link between postcopulatory sexual selection and speciation. Instead, we propose two alternative models that do not require the invocation of complex molecular-physiological conflicts to explain patterns of reproductive isolation and sexual selection: (1) the Rube Goldberg model, in which divergence in prezygotic reproductive behavior and structures alone could rapidly produce incompatibility in viviparous fishes, and (2) the costs associated with viviparity could result in the rapid evolution of female mate preferences and precopulatory indicators of male quality that accelerate the rate of divergence among viviparous fishes. Although these two alternative hypotheses are not mutually exclusive-clearly the morphology of mating structures, male signals, female choice, and the costs of mating in viviparous fishes, all of which are prezygotic mechanisms, are evolutionarily linked-it is perhaps useful to consider each to be an independently testable subset of a general hypothesis of how prezygotic mechanisms of mate choice and reproductive mode affect the tempo of evolution of hybrid inviability. In the future, a more fully realized mathematical model of the VDC hypothesis would provide more precise predictions with which the VDC hypothesis - and alternative hypotheses such as those presented here-could be tested more rigorously in particular experimental systems. Such models would necessarily include parameters that more accurately represent the complex morphological and behavioral characteristics of fish mating systems.

\section{Acknowledgments}

We are grateful to R. Montgomerie, D. N. Reznick, G. G. Rosenthal, and D. Zeh for valuable comments on previous versions of the manuscript. Thanks to B. B. Collette and D. N. Reznick for informative discussion on male ornamentation in the Zenarchopteridae and in Poeciliopsis, respectively, and for generously sharing their forthcoming manuscript on the Zenarchopteridae. Thank you to W. Maddison, M. Mateos, P. Midford, and C. Small for advice and assistance with phylogenetic tests. This work was funded by an individual postdoctoral National Research Service Award to S.W.C. from the National Institute of 
General Medical Sciences, National Institutes of Health, and by a National Science Foundation grant to A.G.J.

\section{Literature Cited}

Anderson, W. D., and B. B. Collette. 1991. Revision of the freshwater viviparous halfbeaks of the genus Hemirhamphodon (Teleostei: Hemiramphidae). Ichthyological Exploration of Freshwaters 2: 151-176.

Awata, S., H. Munehara, and M. Kohda. 2005. Social system and reproduction in a cooperatively breeding cichlid fish (Juliochromis ornatus) in Lake Tanganyika: field observations and parentage analyses. Behavioral Ecology and Sociobiology 58:506-516.

Bekkevold, D., M. M. Hanson, and V. Loeschcke. 2002. Male reproductive competition in spawning aggregations of cod (Gadus morhua, L.). Molecular Ecology 11:91-102.

Bellwood, D. R., L. van Herwerden, and N. Konow. 2004. Evolution and biogeography of marine angelfishes (Pisces: Pomacanthidae). Molecular Phylogenetics and Evolution 33:140-155.

Bernardi, G., G. Bucciarelli, D. Costagliola, D. R. Robertson, and J. B. Heiser. 2004. Evolution of coral reef fish Thalassoma spp. (Labridae). I. Molecular phylogeny and biogeography. Marine Biology 144:369-375.

Birkhead, T. R., and A. P. Møller. 1998. Sperm competition and sexual selection. Academic Press, London.

Bolnick, D. I., and T. J. Near. 2005. Tempo of hybrid inviability in centrarchid fishes (Teleostei: Centrarchidae). Evolution 59:17541767.

Bordenstein, S. R., F. P. O’Hara, and J. H. Werren. 2001. Wolbachiainduced incompatibility precedes other hybrid incompatibilities in Nasonia. Nature 409:707-710.

Borowsky, R., and K. D. Kallman. 1976. Patterns of mating in natural populations of Xiphophorus (Pisces: Poeciliidae) I. X. maculatus from Belize and Mexico. Evolution 30:693-706.

Borowsky, R., and J. Khouri. 1976. Patterns of mating in natural populations of Xiphophorus (Pisces: Poeciliidae) II. X. variatus from Tamaulipas, Mexico. Copeia 1976:727-734.

Boulcott, P. D., K. Walton, and V. A. Braithwaite. 2005. The role of ultraviolet wavelengths in the mate-choice decisions of female three-spined sticklebacks. Journal of Experimental Zoology 208: 1453-1458.

Brembach, M. 1985. Livebearing aquarium fishes. TFH, Neptune City, NJ.

Chao, W., and P. A. D'Amore. 2008. Igf2: epigenetic regulation and role in development and disease. Cytokine and Growth Factor Reviews 19:111-120.

Chapman, D. D., P. A. Prodohl, J. Gelsleichter, C. A. Manire, and M. S. Shivji. 2004. Predominance of genetic monogamy by females in a hammerhead shark, Sphyrna tiburo: implication for shark conservation. Molecular Ecology 13:1965-1974.

Clutton-Brock, T. M., M. Hiraiwa-Hasegawa, and A. Robertson. 1989. Mate choice on fallow deer leks. Nature 340:463-465.

Constantz, G. 1989. Reproductive biology of poeciliid fishes. Pages 33-50 in G. Meff and F. Snelson, eds. Ecology and evolution of livebearing fishes (Poeciliidae). Prentice Hall, Englewood Cliffs, NJ.

Cooper, V. J., and G. R. Hosey. 2003. Sexual dichromatism and female preference in Eulemur fulvus subspecies. International Journal of Primatology 24:1177-1188.
Coyne, J. A., and H. A. Orr. 1989. Patterns of speciation in Drosophila. Evolution 43:362-381.

1997. Patterns of speciation in Drosophila revisited. Evolution 51:295-303.

- 2004. Speciation. Sinauer, Sunderland, MA.

Craul, M., E. Zimmerman, and U. Radespiel. 2004. First experimental evidence for female choice in a nocturnal primate. Primates 45 : 271-274.

Darwin, C. 1871. The descent of man and selection in relation to sex. Random House, New York. Original edition, J. Murray, London.

DeWoody, J. A., D. E. Fletcher, S. D. Wilkins, W. S. Nelson, and J. C. Avise. 2000a. Genetic monogamy and biparental care in an externally-fertilizing fish, the largemouth bass (Micropterus salmoides). Proceedings of the Royal Society B: Biological Sciences 267:2431-2437.

DeWoody, J. A., D. E. Fletcher, S. D. Wilkins, and J. C. Avise. $2000 b$. Microsatellite analyses of parentage and nest guarding in the tessellated darter (Pisces: Percidae). Copeia 2000:740-747.

DeWoody, J. A., D. E. Fletcher, S. D. Wilkins, W. S. Nelson, and J. C. Avise. 2000c. Molecular genetic dissection of spawning, parentage, and reproductive tactics in a population of redbreast sunfish, Lepomis auritus. Evolution 52:1802-1810.

Dierkes, P., M. Taborsky, and U. Kohler. 1999. Reproductive parasitism of broodcare helpers in a cooperatively breeding fish. Behavioral Ecology 10:510-515.

Dobzhansky, T. 1937. Genetics and the origin of species. Columbia University Press, New York.

Dowling, T. E., W. R. Hoeh, G. R. Smith, and W. M. Brown. 1992. Evolutionary relationships of shiners in the genus Luxilus (Cyprinidae) as determined by analysis of mitochondrial DNA. Copeia 1992:306-322.

Durand, J.-D., P. G. Bianco, J. Laroshe, and A. Gilles. 2003. Insight into the origin of endemic Mediterranean ichthyofauna: phylogeography of Chondrostoma genus (Teleostei, Cyprinidae). Journal of Heredity 94:315-328.

Egger, B., B. Obermuller, H. Phiri, C. Sturmbauer, and K. M. Sefc. 2006. Monogamy in the maternally mouthbrooding Lake Tanganyika cichlid fish Tropheus moorii. Proceedings of the Royal Society B: Biological Sciences 273:1797-1802.

Evans, J. P., and A. E. Magurran. 2001. Sperm precedence patterns and predictors of paternity in the Trinidadian guppy. Proceedings of the Royal Society B: Biological Sciences 268:719-724.

Feldheim, K. A., S. H. Gruber, and M. V. Ashley. 2001. Multiple paternity of a lemon shark litter (Chondrichthyes: Carcharhinidae). Copeia 2001:781-786.

- 2004. Reconstruction of parental microsatellite genotypes reveals female polyandry and philopatry in the lemon shark, Negaprion brevirostris. Evolution 58:2332-2343.

Felsenstein, J. 1985. Phylogenies and the comparative method. American Naturalist 125:1-15.

Fessehaye, Y., Z. El-Baily, M. A. Rezk, R. Crooilmans, H. Bovenhuis, and H. Komen. 2006. Mating systems and male reproductive success in Nile tilapia (Oreochromis niloticus) in breeding hapas: a microsatellite analysis. Aquaculture 256:148-158.

Fisher, H. S., R. R. Swaisgood, and H. Fitch-Snyder. 2003a. Countermarking by male pygmy lorises (Nycticebus pygmaeus): do females use odor cues to select mates with high competitive ability? Behavioral Ecology and Sociobiology 53:123-130.

2003b. Odor familiarity and female preferences for males 
in a threatened primate, the pygmy loris (Nycticebus pygmaeus): applications for genetic management of small populations. Naturwissenschaften 90:509-511.

Fiumera, A. C., B. A. Porter, G. D. Grossman, and J. C. Avise. 2002. Intensive genetic assessment of the mating system and reproductive success in a semi-closed population of the mottled sculpin, Cottus bairdi. Molecular Ecology 11:2367-2377.

Fletcher, D. E., E. E. Dakin, B. A. Porter, and J. C. Avise. 2004. Spawning behavior and genetic parentage in the pirate perch (Aphredoderus sayanus), a fish with an enigmatic reproductive morphology. Copeia 2004:1-10.

Gleason, J. M., and M. G. Ritchie. 1998. Evolution of courtship song and reproductive isolation in the Drosophila willistoni complex: do sexual signals diverge the most quickly? Evolution 52:1439-1500.

Haig, D. 1993. Genetic conflicts in human pregnancy. Quarterly Review of Biology 68:495-532.

1996a. Altercation of generations: genetic conflicts of pregnancy. American Journal of Reproductive Immunology 35:226232.

1996b. Gestational drive and the green-bearded placenta. Proceedings of the National Academy of Sciences of the USA 93: 6547-6551.

. 2004. Evolutionary conflicts in pregnancy and calcium metabolism: a review. Placenta 25(suppl.):S10-S15.

- 2006. Intragenomic politics. Cytogenetic and Genome Research 113:68-74.

Hayashi, T. I., M. Vose, and S. Gavrilets. 2007. Genetic differentiation by sexual conflict. Evolution 61:516-529.

Hohoff, C., K. Franzen, and N. Sachser. 2003. Female choice in a promiscuous wild guinea pig, the yellow-toothed cavy (Galea musteloides). Behavioral Ecology and Sociobiology 53:341-349.

Holland, B., and W. R. Rice. 1998. Chase-away sexual selection: antagonistic seduction versus resistance. Evolution 52:1-7.

Hore, T. A., R. W. Rapkins, and J. A. Marshall Graves. 2007. Construction and evolution of imprinted loci in mammals. Trends in Genetics 23:440-448.

Houde, A. 1997. Sex, color, and mate choice in guppies. Princeton University Press, Princeton, NJ.

Huck, W., and E. M. Banks. 1982. Male dominance status, female choice and mating success in the brown lemming, Lemmus trimucronatus. Animal Behaviour 30:665-675.

Jones, A. G., S. Östlund-Nilsson, and J. C. Avise. 1998. A microsatellite assessment of sneaked fertilizations and egg thievery in the fifteenspine stickleback. Evolution 52:848-858.

Jones, A. G., D. Walker, C. Kvarnemo, K. Lindström, and J. C. Avise. $2001 a$. How cuckoldry can decrease the opportunity for sexual selection: data and theory from a genetic parentage analysis of the sand goby, Pomatoschistus minutus. Proceedings of the National Academy of Sciences of the USA 98:9151-9156.

Jones, A. G., D. Walker, K. Lindström, C. Kvarnemo, and J. C. Avise. $2001 b$. Surprising similarity of sneaking rates and genetic mating patterns in two populations of the sand goby experiencing disparate sexual selection regimes. Molecular Ecology 10:461-469.

Katoh, R., H. Munehara, and M. Kohda. 2005. Alternative mating tactics of the substrate brooding cichlid Telmatochromis temporalis in Lake Tanganyika. Zoological Science 22:555-561.

Kellogg, K. A., J. A. Markert, J. R. Stauffer, and T. R. Kocher. 1995. Microsatellite variation demonstrates multiple paternity in lekking cichlid fishes from Lake Malawi, Africa. Proceedings of the Royal Society B: Biological Sciences 260:79-84.
1998. Intraspecific brood mixing and reduced polyandry in a maternal mouth-brooding cichlid. Behavioral Ecology 9:309-312. Klett, V., and A. Meyer. 2002. What, if anything, is a tilapia? mitochondrial ND2 phylogeny of tilapiines and the evolution of parental care systems in the African cichlid fishes. Molecular Biology and Evolution 19:865-883.

Langerhans, R. B., W. J. Rowland, and T. J. Dewitt. 2005. Male genitalia size reflects a tradeoff between attracting mates and avoiding predators in two livebearing fish species. Proceedings of the National Academy of Sciences of the USA 102:7618-7623.

Largiader, C. R., V. Fries, and T. C. M. Bakker. 2001. Genetic analysis of sneaking and egg-thievery on a natural population of the threespined stickleback (Gasterosteus aculeatus L.). Heredity 86:459-468.

Lawton, B. R., L. Sevigny, C. Obergfell, D. Reznick, R. J. O'Neill, and M. J. O'Neill. 2005. Allelic expression of IGF2 in live-bearing, matrotrophic fishes. Development Genes and Evolution 215:207212.

Lennington, S., and K. Egid. 1985 Female discrimination of male odors correlated with male genotype at the T locus: a response to T locus of H-2 locus variability? Behavioral Genetics 15:53-67.

Luo, J., M. Santerra, M. Schartl, and A. Meyer. 2005. Strong reproductive skew among males in the multiple mated swordtail $\mathrm{Xi}$ phophorus multilineatus (Teleostei). Journal of Heredity 96:346355.

Mackiewicz, M., D. E. Fletcher, S. D. Wilkins, B. A. Porter, J. A. DeWoody, and J. C. Avise. 2002. A genetic assessment of parentage in a natural population of dollar sunfish (Lepomis marginatus) based on microsatellite markers. Molecular Ecology 11:1877-1883.

Mackiewicz, M., B. A. Porter, E. E. Dakin, and J. C. Avise. 2005. Cuckoldry rates in the molly miller (Scartella cristata; Blenniidae), a hole-nesting marine fish with alternative reproductive tactics. Marine Biology 148:213-221.

Maddison, W. P. 2000. Testing character correlation using pairwise comparisons on a phylogeny. Journal of Theoretical Biology 202: 195-204.

Maddison, W. P., and D. R. Maddison. 2006. Mesquite: a modular system for evolutionary analysis. Version 1.12. http:// mesquiteproject.org.

Mank, J. E., and J. C. Avise. 2006. Supertree analyses of the roles of viviparity and habitat in the evolution of atherinomorph fishes. Journal of Evolutionary Biology 19:734-740.

Mateos, M. 2005. Comparative phylogeography of livebearing fishes in the genera Poeciliopsis and Poecilia (Poeciliidae: Cyprinodontiformes) in central Mexico. Journal of Biogeography 32:775-780.

Mateos, M., O. I. Sanjur, and R. C. Vrijenhoek. 2002. Historical biogeography of the livebearing fish genus Poeciliopsis (Poeciliidae: Cyprodontiformes). Evolution 56:972-984.

Mayr, E. 1963. Populations, species, and evolution. Harvard University Press, Cambridge, MA.

McComb, K. E. 1991. Female choice for high roaring rates in red deer, Cervus elaphus. Animal Behaviour 41:79-88.

McGrath, J., and D. Soulter. 1984. Completion of mouse embryogenesis requires both the maternal and paternal genomes. Cell 37: 179-183.

McKay, S. J., R. H. Devlin, and M. J. Smith. 1996. Phylogeny of Pacific salmon and trout based on growth hormone type-2 and mitochondrial NADH dehydrogenase subunit 3 DNA sequences. Canadian Journal of Fisheries and Aquatic Sciences 53:1165-1176. McLean, J. E., P. Bentzen, and T. P. Quinn. 2004. Does size matter? 
fitness-related factors in steelhead trout determined by genetic parentage assignment. Ecology 85:2979-2985.

Mehranvar, L., M. Healey, A. Farrell, and S. Hinch. 2004. Social versus genetic measures of reproductive success in sockeye salmon, $\mathrm{On}$ corhynchus mykiss. Evolutionary Ecology Research 6:1167-1181.

Meisner, A. D. 2001. Phylogenetic systematics of the viviparous halfbeak genera Dermogenys and Nomorhamphus (Teleostei: Hemiramphidae: Zenarchopterinae). Zoological Journal of the Linnaean Society 133:199-283.

Meisner, A. D., and J. R. Burns. 1997. Viviparity in the halfbeak genera Dermogenys and Nomorhamphus (Teleostei: Hemiramphidae). Journal of Morphology 234:295-317.

Mendelson, T. C. 2003. Sexual isolation evolves faster than hybrid inviability in a diverse and sexually dimorphic genus of fish (Percidae: Etheostoma). Evolution 57:317-327.

Morison, I., J. P. Ramsayand, and H. G. Spencer. 2005. A census of mammalian imprinting. Trends in Genetics 21:457-465.

Near, T. J., and M. F. Bernard. 2004. Rapid allopatric speciation in logperch darters (Percidae: Percina). Evolution 58:2798-2808.

Near, T. J., D. I. Bolnick, and P. C. Wainwright. 2005. Fossil calibrations and molecular divergence time estimates in centrarchid fishes (Teleostei: Centrarchidae). Evolution 59:1768-1782.

Neff, B. D. 2001. Genetic paternity analysis and breeding success in bluegill sunfish (Lepomis macrochirus). Journal of Heredity 92:111119.

O’Neill, M. J., B. R. Lawton, M. Mateos, D. M. Carone, G. C. Ferreri, T. Hrbek, R. W. Meredith, D. N. Reznick, and R. J. O’Neill. 2007. Ancient and continuing Darwinian selection on insulin-like growth factor II in placental fishes. Proceedings of the National Academy of Sciences of the USA 104:12404-12409.

Parker, A., and I. Kornfield. 1996. Polygynandry in Pseudotropheus zebra, a cichlid fish from Lake Malawi. Environmental Biology of Fishes 47:345-352.

Parker, G. A. 2006. Sexual conflict over mating and fertilization: an overview. Philosophical Transactions of the Royal Society B: Biological Sciences 361:235-259.

Porter, B. A., A. C. Fiumera, and J. C. Avise. 2002. Egg mimicry and alloparental care: two mate attracting tactics by which nesting striped darter (Etheostoma virgatum) males enhance reproductive success. Behavioral Ecology and Sociobiology 51:350-359.

Read, A. F., and S. Nee. 1995. Inference from binary comparative data. Journal of Theoretical Biology 173:99-108.

Reece-Engel, C. 1988. Female choice of resident male rabbits Oryctolagus cuniculus. Animal Behaviour 36:1241-1242.

Reik, W., and J. Walter. 2001. Genomic imprinting: parental influence on the genome. Nature Reviews Genetics 2:21-32.

Reznick, D. N., and D. B. Miles. 1989. Review of life history patterns in poeciliid fishes. Pages 125-148 in G. K. Meffe and F. F. Snelson Jr., eds. Ecology and evolution of livebearing fishes (Poeciliidae). Prentice Hall, Englewood Cliffs, NJ.

Reznick, D. N., M. Mateos, and M. S. Springer. 2002. Independent origins and rapid evolution of the placenta in the fish genus Poeciliopsis. Science 298:1018-1020.

Reznick, D. N., R. Meredith, and B. B. Collette. 2007. Independent evolution of complex life history adaptations in two families of fishes, live-bearing halfbeaks (Zenarchopteridae, Beloniformes) and Poeciliidae (Cyprinodontiformes). Evolution 61:2570-2583.

Rick, I. F., and T. C. M. Bakker. 2008. UV wavelengths make female three-spined sticklebacks (Gasterosteus aculeatus) more attractive for males. Behavioral Ecology and Sociobiology 62:439-445.
Rick, I. F., R. Modarressie, and T. C. M. Bakker. 2006. UV wavelengths affect female mate choice in three-spined sticklebacks. Animal Behaviour 71:307-313.

Rosen, D. E. 1960. Middle American poeciliid fishes of the genus Xiphophorus. Bulletin of the Florida State Museum of Biological Science 5:57-242.

Rosen, D. E., and R. M. Bailey. 1963. The poeciliid fishes (Cyprinodontiformes), their structure, zoogeography and systematics. Bulletin of the American Museum of Natural History 126:1-176.

Ryan, M. J., and G. G. Rosenthal. 2001. Variation and selection in swordtails. Pages 133-148 in L. A. Dugatkin, ed. Model systems in behavioral ecology. Princeton University Press, Princeton, NJ.

Saville, K. J., A. M. Lindley, E. G. Maries, J. C. Carrier, and H. L. Pratt. 2002. Multiple paternity in the nurse shark, Ginglymostoma cirratum. Environmental Biology of Fishes 63:347-351.

Schrader, M., and J. Travis. 2008. Testing the viviparity-driven-conflict hypothesis: parent-offspring conflict and the evolution of reproductive isolation in a poeciliid fish. American Naturalist 172: 806-817.

Scrimshaw, N. S. 1944. Superfetation in poeciliid fishes. Copeia 1944: $180-183$.

Smith, E. J., J. C. Partridge, K. N. Parsons, E. M. White, I. C. Cuthill, A. T. D. Bettett, and S. C. Church. 2002. Ultraviolet vision and mate choice in the guppy (Poecilia reticulata). Behavioral Ecology 13:11-19.

Sokal, R. R., and F. J. Rohlf. 1995. Biometry. W. H. Freeman, New York.

Soucy, S., and J. Travis. 2003. Multiple paternity and population genetic structure in natural populations of the poeciliid fish, Heterandria formosa. Journal of Evolutionary Biology 16:1328-1336.

Surani, M., S. C. Barton, and M. L. Norris. 1984. Development of reconstituted mouse eggs suggests imprinting of the genome during gametogenesis. Nature 308:548-550.

Takahashi, H., and A. Goto. 2001. Evolution of East Asian ninespine sticklebacks as shown by mitochondrial DNA control region sequences. Molecular Phylogenetics and Evolution 21:135-155.

Taylor, M. I., J. I. Morley, C. Rico, and S. Balshine. 2003. Evidence for genetic monogamy and female-biased dispersal in the biparental mouthbrooding cichlid Eretmodus cyanostictus from Lake Tanganyika. Molecular Ecology 12:3173-3177.

Thibault, R. E., and R. J. Schultz. 1978. Reproductive adaptations among viviparous fishes (Cyprinodontiformes: Poeciliidae). Evolution 32:320-333.

Tilghman, S. M. 1999. The sins of the fathers and mothers: genomic imprinting in mammalian development. Cell 96:185-193.

Trexler, J. C., J. Travis, and A. Dinep. 1997. Variation among populations of the sailfin molly in the rate of concurrent multiple paternity and its implications for mating-system evolution. Behavioral Ecology and Sociobiology 40:291-305.

Turner, B. J., B.-L. H. Brett, and R. R. Miller. 1980. Interspecific hybridization and the evolutionary origin of a gynogenetic fish, Poecilia formosa. Evolution 34:917-922.

Turner, C. L. 1937. Reproductive cycles and superfetation in poeciliid fishes. Biological Bulletin 72:145-164.

. 1940. Superfetation in viviparous cyprinodont fishes. Copeia 1940:88-91.

Vrana, P. B. 2007. Genomic imprinting as a mechanism of reproductive isolation in mammals. Journal of Mammalogy 88:5-23.

Waitt, C., A. C. Little, S. Wolfensohn, P. Honess, A. P. Brown, H. M. Buchanan-Smith, and D. I. Perrett. 2003. Evidence from rhesus 
macaques suggests that male coloration plays a role in female primate mate choice. Proceedings of the Royal Society B: Biological Sciences 270(suppl.):S144-S146.

Wischnath, L. 1993. Atlas of livebearers of the world. TFH, Neptune City, NJ.

Withler, R. E., J. R. King, J. B. Marliave, B. Beaith, S. R. Li, K. J. Supernaulta, and K. M. Miller. 2004. Polygamous mating and high levels of genetic variation in lingcod, Ophiodon elongatus, of the Strait of Georgia, British Columbia. Environmental Biology of Fishes 69:345-357.

Zane, L., W. S. Nelson, A. G. Jones, and J. C. Avise. 1999. Micro- satellite assessment of multiple paternity in natural populations of a live-bearing fish, Gambusia holbrooki. Journal of Evolutionary Biology 12:61-69.

Zeh, D. W., and J. A. Zeh. 2000. Reproductive mode and speciation: the viviparity-driven conflict hypothesis. Bioessays 22:938-946.

Zeh, J. A., and D. W. Zeh. 2008. Vivparity driven conflict: more than meets the fly. Annals of the New York Academy of Sciences 1133: $126-148$.

Associate Editor: Ellen D. Ketterson Editor: Monica A. Geber 